\title{
PREGNANCY AND LABOUR IN HIGH TRAUMATIC SPINAL CORD LESIONS
}

\author{
A. B. Rossier, M. RufFieux and W. H. ZIEGLER*
}

\section{FOREWORD}

This article is dedicated as a special tribute to Sir Ludwig Guttmann, who more than a quarter of a century ago initiated rational treatment for spinal cord injury patients. With his wide medical knowledge, and very keen interest, he focused attention internationally on this particular type of disability.

However, Sir Ludwig Guttmann's interest did not stop at saving patients' lives and increasing their life expectancy, it required involving the very beginning of Life, in other words conception, pregnancy and birth. All three of these features were examined closely by him. It seemed to me therefore justified to devote an article dealing with pregnancy and labour in patients with traumatic tetraplegia, as a tribute to Sir Ludwig.

Bors (I948) and Munro (1948) in the United States and Guttmann (1953) in Europe have been pioneers in the treatment and in the socio-professional rehabilitation of spinal cord patients. Since then such positive and favourable results have been reached in this field that there is no need any more to discourage young paraplegic women from getting married. As a result of this positive attitude, spinal cord units are admitting more and more pregnant patients desirous of having children. According to the few publications dealing with such cases (Ware, I934; Hutchinson and Vasicka, I962; Jung and Schmidt, I962; Guttmann, I963; Robertson, I963; Jackson, I964; Guttmann, et al. 1965; Comarr, I966), experience has shown that paraplegic and also tetraplegic women are quite able to continue pregnancy up to term. However, there are particular problems which are related to pregnancy in spinal cord patients as well as specific complications such as autonomic hyperreflexia which may occur during delivery. Both conditions require close team work between the 'paraplegist' and the obstetrician.

We had to face these problems some months ago when a 32-year-old patient of ours, living in Tunisia, asked for advice upon becoming pregnant. Before sustaining an incomplete tetraplegia by car accident on 21 August 1964, the patient had delivered vaginally a normal girl weighing $3800 \mathrm{~g}$. In 1966 she underwent an interruptio graviditatis, and in her letter dated 20 March 1967, she expressed her fear of another interruptio because the physicians treating her were absolutely against her becoming pregnant.

On I3 October 1967, during the 35th week of amenorrhoea, the patient entered the Paraplegic Centre. During delivery, cardio-vascular changes related to uterine activity were studied by electrocardiograms and uterine contractions were recorded by external tocodynamometry; the findings are presented in this paper:

Case Report. Following fractures of $\mathrm{C}_{5}, \mathrm{C}_{6}$ and $\mathrm{C}_{7}$ the patient sustained an atypical anterior spinal cord syndrome (incomplete sensory $\mathrm{C}_{7}-\mathrm{C} 8$ and complete motor

* Paraplegic Centre (Dr. A. B. Rossier) from the University Institute for Physical Medicine and Rehabilitation (Prof. G. H. Fallet), the University Clinic for Gynecology and Obstetrics (Prof. H. de Watteville), Cantonal Hospital, Geneva and the University Medical Clinic (Prof. A. Labhart, Prof. P. Frick), Cantonal Hospital, Zurich, Switzerland. 
C8-TI, bilaterally) (fig. I). Another important feature enabling the patient to feel the beginning of labour pains was the preservation of normal sensation of micturition and defaecation, which, however, could not be controlled voluntarily. The muscles of the shoulder girdles and of the arms were found to be normal*; the muscles of the forearms and of the wrists were between grades $3+$ and $4+$. All muscles of the fingers were at 0 with exception of the extensor communis and of the lumbricales at 3. All reflexes in the upper and lower extremities were present, symmetrical and not exaggerated. On both

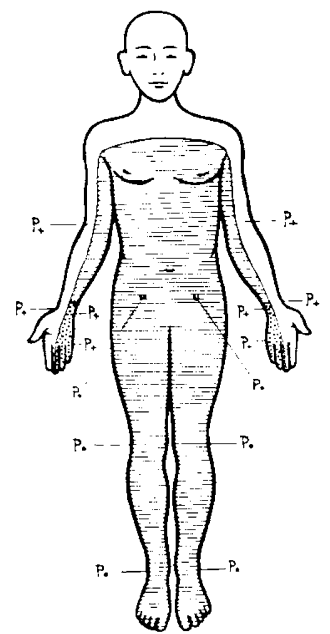

Thermanaesthesia
Analgesia
Hypoalgesia
Vibration sense P+or Po

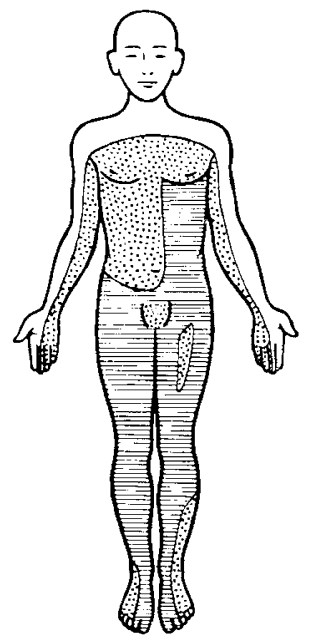

Anaesthesia $\equiv$.. Hypoaesthesia ::.:.:.:.:.:.:

FIG. I

Sensory findings. $\mathrm{Al} \ldots \mathrm{i}$ i940. Date of examination I4. I0.1967.

sides there was a Babinski sign with withdrawal. Reflexes (anal and bulbocavernosus) having their synapses within the conus medullaris could also be found. The obstetrical examination did not show any abnormality.

The haemoglobin level was 43 per cent.; further investigations about this abnormally low level revealed a minor thalassemia with marked increase of Hb.F. and A2 (fig. 2). Fortunately this anaemia was well tolerated. Three whole-blood transfusions were given before delivery but had little effect on the haemoglobin ratio.

As our patient had an incomplete lesion with preservation of bladder, bowel and uterine sensation, she had the normal feeling of small contractions at the end of her pregnancy, and during the 39th week the cervix became progressively softer and permeable to the finger. As the maturity of the cervix was satisfactory, delivery was initiated for better observation of the patient. Rapid dilatation of the cervix took place 70 minutes after rupture of the water sac and, as the abdominal muscles were completely paralysed, the vacuum extractor was used. As the umbilical cord was wrapped around the child's neck this decision appeared to have been correct. On I November I967, the patient delivered a boy weighing $3070 \mathrm{~g}$. A Io without episiotomy. Oxytocics were given prophylactically because of the low haemoglobin ratio, and blood loss was limited to $150 \mathrm{~cm}^{3}$ by these means. There were no after-birth complications of either mother or child.

* Nomenclature of the British Medical Research Council (I942). 
From the beginning of labour uterine contractions were described by the patient as similar to those she had experienced during her first delivery (that is before she became a tetraplegic). These contractions were accompanied by sweating of the upper part of

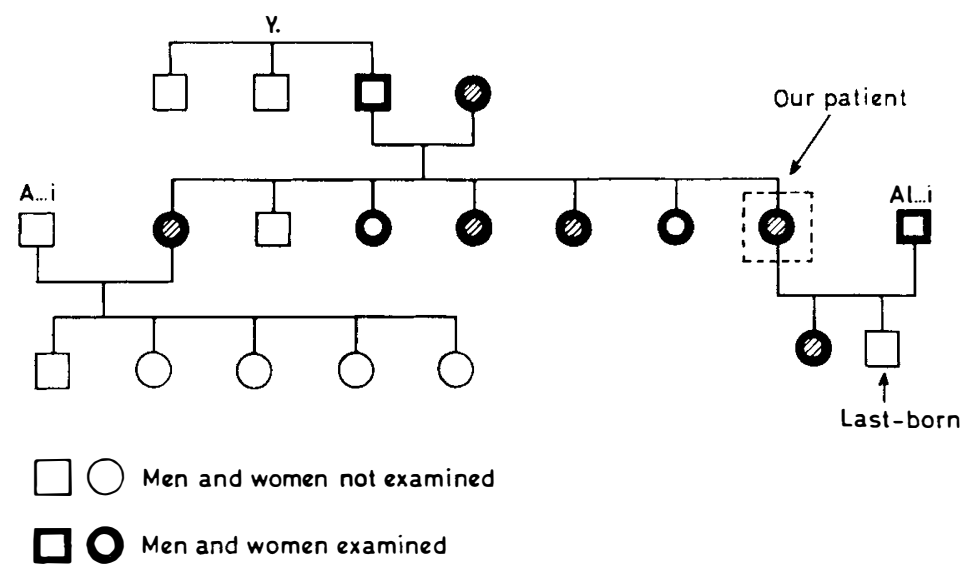

Minor thalassemia

FIG. 2

Genealogical tree of the Y-Al ... i family.

the body and by synchronous cardiovascular changes: headaches, slight elevation of blood pressure and bradycardia (it should be noted that there was no cardiac arrythmia at any time during delivery).

\section{DISCUSSION}

During the pregnancy of a paraplegic woman there are two usual complications which have to be watched for:

I. Urinary infection, which is frequent and long lasting and may become particularly serious during pregnancy. If kidney function is satisfactory such infection does not by itself represent an impediment to pregnancy. When the patient entered the centre catheterised urine showed neither albumen nor leucocytes, the bacteria count being 300 organisms per $\mathrm{cm}_{3}$ (Proteus mirabilis). After treatment the patient went home with a sterile urine.

2. Anaemia has to be watched for in spinal cord patients as it decreases tissue resistance to pressure and infection and therefore enhances the danger of pressure sores and of pyelonephritic exacerbations. When the haemoglobin is below 80 per cent. it is advisable to give blood transfusions and perhaps also intravenous injections of iron. Oral therapy has the disadvantage of increasing constipation, which is in any case common in non-paraplegic women, and of reinforcing the intestinal dysfunction already initiated by the spinal cord lesion.

It may be difficult to know when labour is beginning in patients with a complete lesion above Tio (Robertson, 1963), who show an absence of nociceptive sensations to uterine contractions and may have a premature delivery in unfavourable conditions. Patients whose initial labour period can be known only through daily examinations of the cervix should be hospitalised by the 32nd week, as a dilated cervix is often to be found by the $34^{\text {th }}$ week of pregnancy. 
Our patient had a spinal cord lesion above $\mathrm{T}_{5}$, i.e. above the splanchnic outflow, and as she previously had displayed signs of autonomic hyper-reflexia for bladder and bowel function the same was to be expected during delivery as we know that this syndrome is mainly caused by distension of hollow viscera (Guttmann \& Whitteridge, 1947; Bors \& French, 1952). The usual manifestations are severe paroxysmal hypertension, marked diaphoresis, headaches, pilo-erection, bradycardia and blockage of nasal air passages (Guttmann's sign, 1947). It is thought that afferent stimuli arise in the bladder, bowel and genital areas and ascend in the spinothalamic tracts and posterior columns. Reflex motor outflow through neurones in the lateral horns causes vasoconstriction leading to hypertension. The elevation of pressure will be appreciated by receptors from the aortic arch and carotid sinus, and efferent impulses will be sent to the sinoauricular node via the tenth cranial nerves in order to correct the hypertension. Since these pathways are intact, bradycardia results. However, because of the interruption of the medullary pathways at the level of the spinal cord injury, efferent stimuli will not reach the vasomotor centres in the medulla and no change in blood pressure will ensue.

Guttmann and Whitteridge (1947) have studied the relationship between bladder distension on the one hand and sweating and cardiovascular activity on the other in spinal cord injury patients, and they suggest that adrenaline might be liberated and thus be responsible for some of the observed phenomena. Garnier and Gertsch (1964) have shown that autonomic hyperreflexia was in fact accompanied by liberation of catecholamines.

The symptoms of autonomic hyperreflexia shown by our patient decreased considerably and even disappeared during the resting periods between contractions; they increased close to the end of labour and reached a climax just before the time of expulsion (fig. 3). However, they never became so critical that ganglioplegic medication, such as hexamethonium chloride, was necessary. These observations differ from the cardiovascular modifications which can be seen during the labour of normal pregnant women. During uterine contractions Caldeyro-Barcia (1958) has recorded an increase in blood pressure ranging from 10 to $20 \mathrm{~mm}$. $\mathrm{Hg}$. Adams and Alexander (1958), through a technique employing diluted colouring materials, noted that during normal uterine contractions cardiac output increases by 19.7 per cent., and mean arterial blood pressure increases from 94 to $102 \mathrm{~mm}$. Hg with a simultaneous pulse acceleration of 14 per cent.

To our knowledge, the simultaneous recording of uterine activity by external tocodynamometry with electrocardiogram and measurements of blood pressure and pulse has not yet been used in the study of labour in traumatic spinal cord lesions. In view of the interesting clinical features shown by our patient the present shortterm investigation was undertaken not only to corroborate the few previous reports dealing with the same topic but also to try to substantiate the findings of Garnier and Gertsch (1964) concerning the relationship between autonomic hyperreflexia and the excretion of catecholamines.

Study of the blood pressure of our patient revealed that it started to rise a few seconds after uterine contractions began. Garnier and Gloor (1967) made similar observations during uninhibited activity of the neurogenic bladder in high spinal cord lesions. Guttmann and Whitteridge (1947) found that during the rapid filling of the bladder, there is a time lapse varying from 5 to 8 seconds before vasoconstriction begins in the fingers and before there is a rise in blood pressure. It 
has been demonstrated by Garnier et al. (I964) that according to Cannon and Rosenblueth's law of denervation (I949), and possibly also according to the study of Hertting's et al. (I96I),* small quantities (two to five gamma per minute) of
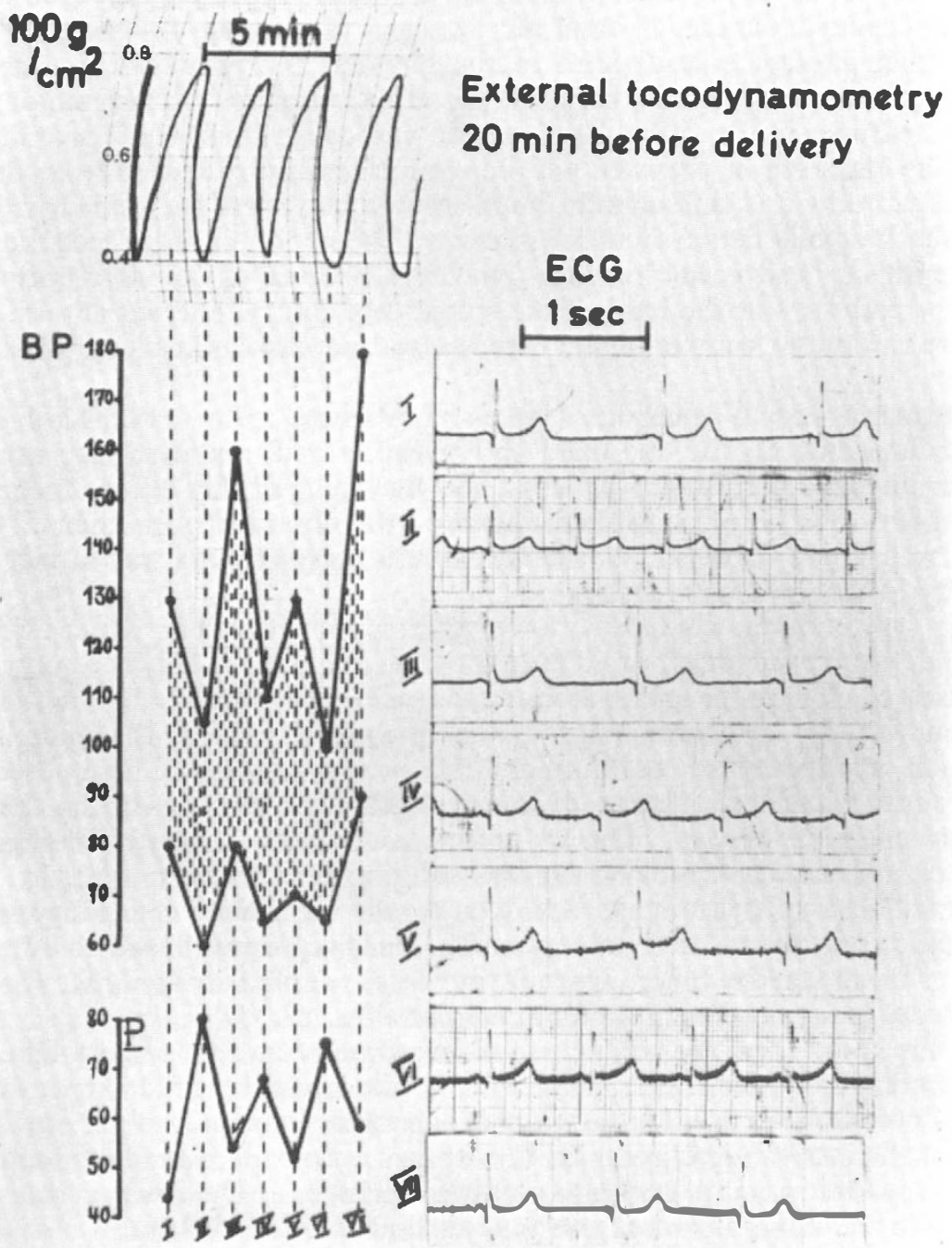

FIG. 3

injected noradrenaline in high spinal cord lesions are able to increase mean blood pressure by 47 to 68 per cent. Moreover, it has been shown by Garnier and Gertsch (I964) that there is some relation between the elevation of the blood pres-

* This study demonstrates that it is impossible for sympathetic nerve tissue (after denervation), to store the noradrenaline that circulates in the blood. 
sure and the excretion level of noradrenaline but that there is none between the blood pressure and the excretion level of adrenaline.

These observations point to the role played by the stimulation of the sympathetic system with liberation of noradrenaline in autonomic hyperreflexia. Reserpine is known to deplete the stock of catecholamines in the sympathetic nerveendings and to suppress autonomic hyperreflexia. Per contra, phentolamine (Regitine) appears to have no effect upon autonomic hyperreflexia (Kurnick, 1956). The rapidity of the variations in blood pressure during bladder filling and emptying on the one hand, and uterine contractions and relaxation on the other, is in accordance with the fact that catecholamines are inactivated rapidly at the nerve-ending sites as well as with the law of denervation.

It must still be noted that the phenomena of autonomic hyperreflexia, particularly the hypertension, became much more accentuated just before delivery and this is similar to what is known to occur during progressive bladder filling in high spinal lesions. Although we have not made estimations of catecholamines in the urine of our patient, we feel that there is some foundation for suggesting that a parallelism between the degree of activity of the uterus and the level of the catecholamines excretion exists. A similar correlation during bladder activity has been found by Garnier and Gertsch (1964). In other words, we believe that the degree of the symptoms seen in autonomic hyperreflexia are in direct proportion to the intensity of the afferent impulses, which in turn are responsible for the increase in the catecholamines excretion. A possible potentiation from the afferent stimuli recruited in the spinal cord remains to be investigated.

\section{CONCLUSION}

During pregnancy in paraplegics and tetraplegics it is necessary to watch for urinary infection, to correct anaemia and to prevent pressure sores. During labour in patients with a lesion at or above $\mathrm{T}_{4}-\mathrm{T}_{5}$, the symptoms of autonomic hyperreflexia should be known by the obstetricians so that they do not confuse them with pre-eclampsia.

\section{SUMMARY}

The case history of the successful delivery of a tetraplegic patient is presented by the authors, who also discuss the problems related to pregnancy and labour in spinal cord lesions. Autonomic hyperreflexia phenomena in high spinal cord lesions are stressed and the role of catecholamines excretion is underlined in this syndrome.

\section{REFERENCES}

Adams, J. Q. \& Alexander, A. M. (1958). Obstet. Gynec. 12, 542.

Bors, E. (I948). Spinal cord injuries. Vet. Adm. Tech. Bull. I 0, 503.

Bors, E. \& French, J. D. (1952). A.M.A. Archs Surg. 64, 803.

CALDEYRo-BARCIA, R. (I958). Uterine contractility in obstetrics. Second Internat. Wld Congr. int. Fed. Gynec. Obstet., Montreal, r, 65.

Cannon, W. B. \& Rosenblueth, A. (1949). The Supersensitivity of denervated structures. $A$ Law of Denervation. New York: Macmillan.

Comarr, A. E. (I966). Med. Servs F. Can. 22, 65 I.

GARNIER, B. \& GERTSCH, R. (I964). Schweiz. med. Wschr. 94, I 24.

Garnier, B., Gertsch, R. \& Steinmann, B. (I964). Cardiologia, 44, 167.

Garnier, B. \& Gloor, J. (I967). Schweiz. med. Wschr. 97, 309. 
GuttmanN, L. (1953). The treatment and rehabilitation of patients with injuries of the spinal cord. In: Cope, Z. History of the Second World War, Surgery, ed. Cope Z, p. 422. London: H.M. Stationery Office.

Guttmann, L. (1963). Proc. R. Soc. Med. 56, 383.

GutTMANN, L. \& WhitTERIDGe, D. (1947). Brain, 70, 36I.

Guttmann, L., Frankel, H. L. \& Paeslack, V. (I965). Int. F. Paraplegia, 3, I44.

Hertting, G., Axelrod, J., Kopin, I. J. \& Whithby, L. G. (I96I). Nature, Lond., 189, 66. Hutchinson, H. T. \& Vasicka, A. (I962). Obstet. Gynec. 20, 675.

JaCKson, F. E. (1964). Obstet. Gynec, 23, 620.

Jung, H. \& SchmidT, K. (1962). Zentbl. Gynaek. 84, I 105.

KurNiCK, N. B. (1956). Ann. intern. Med. 44, 678.

Medical Research Council (1942). Aids to the investigation of Peripheral Nerve Injuries M.R.C. War Memorandum No. 7.

MunRo, D. (1948). Am. F. Surg. 75, 3.

Robertson, D. N. S. (1963). Proc.R. Soc. Med. 56, 38 I.

WARE, H. H. (1934). F. Am. med. Ass. 102, I 33. 